\title{
A3 Adenosine Receptor Agonist Reduces Brain Ischemic Injury and Inhibits Inflammatory Cell Migration in Rats
}

\author{
In-Young Choi, ${ }^{*}$ Jae-Chul Lee, ${ }^{\dagger}$ Chung Ju, ${ }^{*}$ \\ Sunyoung Hwang, ${ }^{*}$ Geum-Sil Cho, ${ }^{*}$ \\ Hyuk Woo Lee, ${ }^{\ddagger}$ Won Jun Choi, ${ }^{\S}$ \\ Lak Shin Jeong, ${ }^{\ddagger}$ and Won-Ki Kim* \\ From the Department of Neuroscience," College of Medicine, \\ Korea University, Seoul; the Clinical Research Institute, ${ }^{\dagger}$ Seoul \\ National University Hospital, Seoul; the Department of \\ Bioinspired Science and College of Pharmacy, ${ }^{\ddagger}$ Ewha Womans \\ University, Seoul; and the College of Pharmacy, ${ }^{\S}$ Dongguk \\ University, Goyang-si, Republic of Korea
}

A3 adenosine receptor (A3AR) is recognized as a novel therapeutic target for ischemic injury; however, the mechanism underlying anti-ischemic protection by the A3AR agonist remains unclear. Here, we report that 2-chloro- $N^{6}$-(3-iodobenzyl)-5'-N-methylcarbamoyl$4^{\prime}$-thioadenosine (LJ529), a selective A3AR agonist, reduces inflammatory responses that may contribute to ischemic cerebral injury. Postischemic treatment with LJ529 markedly reduced cerebral ischemic injury caused by 1.5-hour middle cerebral artery occlusion, followed by 24-hour reperfusion in rats. This effect was abolished by the simultaneous administration of the A3AR antagonist MRS1523, but not the A2AAR antagonist SCH58261. LJ529 prevented the infiltration/migration of microglia and monocytes occurring after middle cerebral artery occlusion and reperfusion, and also after injection of lipopolysaccharides into the corpus callosum. The reduced migration of microglia by $\mathrm{LJ} 529$ could be related with direct inhibition of chemotaxis and down-regulation of spatiotemporal expression of Rho GTPases (including Rac, Cdc42, and Rho), rather than by biologically relevant inhibition of inflammatory cytokine/chemokine release (eg, IL-1 $\beta$, TNF- $\alpha$, and MCP-1) or by direct inhibition of excitotoxicity/oxidative stress (not affected by LJ529). The present findings indicate that postischemic activation of $A 3 A R$ and the resultant reduction of inflammatory response should provide a promising therapeutic strategy for the treatment of ischemic stroke. (Am J Pathol 2011, 179:2042-2052; DOI: 10.1016/j.ajpath.2011.07.006)

Excitotoxicity, peri-infarct depolarization, oxidative stress, apoptosis, and inflammation contribute to the development of cerebral injury after ischemia. ${ }^{1}$ To develop effective therapeutic strategies for postischemic brain injury, it is crucial to understand the highly diverse temporal profiles (eg, onset and duration) of these individual factors and to interrupt their pathophysiological cascades. The $N$-methyl-D-aspartate (NMDA) receptor blocker MK-801 markedly reduces ischemic brain injury; however, MK-801 has a brief therapeutic time window: the neuroprotective effect of MK-801 is obtained only when therapy is given within at most 1 hour after the onset of focal ischemia in rats and gerbils. ${ }^{2,3}$ Furthermore, MK-801 only postpones postischemic neuronal death; it does not improve either neurological recovery or endpoint cell survival at weeks after treatment. ${ }^{4,5}$ Similarly, $\alpha$-amino-3-hydroxy-5-methyl-4-isoxazole propionic acid (AMPA) receptor antagonists also did not significantly protect neuronal loss at 28 days after middle cerebral artery occlusion (MCAO). ${ }^{6}$ This short therapeutic window and lack of long-term effect of NMDA or AMPA receptor antagonists suggests that these receptors play only a transient role in the early ischemic cascade. Thus, some pathophysiological

Supported by grants from Brain Research Center of the $21^{\text {st }}$ Century Frontier Research Program (2010K000808 to W.-K.K.) the Bio \& Medical Technology Development Program (No. 2011-0019440) and from Midcareer Researcher Program (2010-0026203 to L.S.J.) through the National Research Foundation funded by the Ministry of Education, Science and Technology, Republic of Korea.

Accepted for publication July 1, 2011.

I.-Y.C, and J.-C.L. contributed equally to the present work.

Supplemental material for this article can be found at http://ajp. amjpathol.org or at doi: 10.1016/j.ajpath.2011.07.006.

Address reprint requests to Won-Ki Kim, Ph.D., Department of Neuroscience, College of Medicine, Korea University, Anamdong-5-ga, Seongbuk-gu, Seoul 136-705, Republic of Korea; or Lak Shin Jeong, Ph.D. Department of Bioinspired Science and College of Pharmacy, Ewha Womans University, Seoul 120-750, Republic of Korea. E-mail: wonki@ korea.ac.kr or lakjeong@ewha.ac.kr. 
processes that are not affected by one of these treatments are thought to contribute to the delayed cerebral ischemic damage. In this context, much attention has been paid to inflammation, which starts after excitotoxicity and lasts for up to several days and even weeks, as an attractive therapeutic target to prevent the evolution of massive tissue damage in ischemia. ${ }^{7}$

The $\mathrm{A} 3$ adenosine receptor, one of the four adenosine receptor subtypes ( $A 1, A 2 A, A 2 B$, and $A 3$ ), is widely distributed in human and rat brain. ${ }^{8,9}$ Expression of $A 3 A R$ is reported to increase in activated inflammatory cells and modulate their activities ${ }^{10,11}$ Moreover, the A3AR agonists are known to have anti-inflammatory effects in various animal models. ${ }^{12-14}$ Recently, several studies using A3AR knockout mice support the possibility of A3AR as a new target to relieve cerebral ischemic injury. ${ }^{15,16}$ Furthermore, although their effects are variable, depending on experimental conditions (eg, dosage, time window, administration route, location or severity of ischemic injury, and experimental models), administration of A3AR agonists before or immediately after ischemic insults was shown to significantly protect brain tissues in rodent ischemic models. ${ }^{15,17,18}$ The underlying mechanism, however, remains largely unknown.

In the present study, therefore, we investigated the anti-ischemic mechanism of the selective A3AR agonist LJ529 [2-chloro- $N^{6}$-(3-iodobenzyl)-5'-N-methylcarbamoyl4'-thioadenosine], a 4'-thio analog of the well-known ClIB-MECA. Cl-IB-MECA displays inhibition constant $K_{\mathrm{i}}$ values of 820,470 , and $0.33 \mathrm{nmol} / \mathrm{L}$ for $\mathrm{rA} 1 \mathrm{AR}$, rA2AAR, and rA3AR, respectively. ${ }^{19}$ For human adenosine receptors, the $K_{\mathrm{i}}$ values of CI-IB-MECA are 220, 5400, and $1.4 \mathrm{nmol} / \mathrm{L}$ for hA1AR, hA2AAR, and hA3AR, respectively. ${ }^{20}$ We previously showed that LJ529 possesses higher potency and better selectivity to human A3AR than CI-IB-MECA does: the $K_{i}$ values of LJ529 are $0.38 \mathrm{nmol} / \mathrm{L}$ at $\mathrm{hA} 3 \mathrm{AR}$, but only 193 and $223 \mathrm{nmol} / \mathrm{L}$ at hA1AR and hA2AAR, respectively. ${ }^{21}$ In the present study, we found that intraperitoneal injection of LJ529 at 2 and 7 hours after ischemia (ie, 0.5 and 5.5 hours after starting reperfusion) markedly reduced cerebral ischemic injury, and that this anti-ischemic effect might be related to reduced migration of inflammatory cells into the ischemic lesion via suppression of polarized expression of Rho GTPases.

\section{Materials and Methods}

\section{Animals}

Sprague-Dawley male rats (260 to 270 g; Charles River Laboratories International, Seoul, Korea) were acclimated to their environment for 5 days before use. All experimental procedures using animals were in accordance with the NIH Guide (7th Edition) for the Care and Use of Laboratory Animals and were approved by the Committee of Korea University College of Medicine.

\section{Focal Cerebral Ischemia Model}

Rats were anesthetized with $3.0 \%$ isoflurane in $\mathrm{N}_{2} \mathrm{O}$ and $\mathrm{O}_{2}(70: 30 \mathrm{v} / \mathrm{v})$ mixture via facemask and were maintained in $2 \%$ isoflurane. Focal cerebral ischemia was achieved by right-sided endovascular MCAO, as described previously. ${ }^{22}$ Briefly, a 3-0 heat-blunted monofilament nylon suture (Ethicon Johnson \& Johnson, Brussels, Belgium) were inserted into the lumen of the right external carotid artery stump and advanced $17.5 \mathrm{~mm}$ into the internal carotid artery to occlude the ostium of the MCA. The suture was removed after 1.5 hours to allow animals to recover. Sham-operated controls were subjected to the same surgical procedures, except for MCAO. Throughout experiments, the body temperature was monitored with a rectal thermometer and maintained at $37^{\circ} \mathrm{C} \pm$ $0.3^{\circ} \mathrm{C}$ with heating pads. Physiological values were measured 15 minutes before MCAO and at 15 minutes after reperfusion. Mean arterial blood pressure was monitored for 5 minutes using a DigiMed blood pressure analyzer (Micro-Med, Louisville, $\mathrm{KY}$ ). Blood pH, $\mathrm{PaO}_{2}, \mathrm{PaCO}_{2}$, and glucose were monitored using an automatic $\mathrm{pH} / \mathrm{blood}$ gas analyzer (Ciba Corning Diagnostics, Medfield, MA). LJ529 was intraperitoneally administrated to rats twice (1 or $2 \mathrm{mg} / \mathrm{kg}$ for each) at 2 and 7 hours after starting MCAO (ie, 0.5 and 5.5 hours after reperfusion). If necessary, either the A3AR antagonist MRS1523 $\left(K_{\mathrm{i}}=113 \mathrm{nmol} / \mathrm{L}\right.$ for $\mathrm{rA3AR}^{23} ; 1 \mathrm{mg} / \mathrm{kg}$, i.p.) or the A2AAR antagonist SCH58261 $\left(K_{\mathrm{i}}=1.3 \mathrm{nmol} / \mathrm{L}\right.$ for rA2AAR ${ }^{24} ; 70 \mu \mathrm{g} / \mathrm{kg}$, i.p. $)$ was simultaneously administrated with LJ529. The dose of each antagonist used in the present study was determined based on the in vivo effect observed in previous studies ${ }^{25-27}$ and in our preliminary experiments. At doses used in the present study, antagonists alone did not show any effect on infarction size. All in vivo experiments and the subsequent data analysis were performed in a double-blind and randomized manner.

\section{Microinjection of LPS into Corpus Callosum}

After rats were anesthetized with chloral hydrate (300 $\mathrm{mg} / \mathrm{kg}$ ), LPS (Escherichia coli serotype 055:B5; SigmaAldrich, St. Louis, MO; $5 \mu \mathrm{g} / 5 \mu \mathrm{L}$ ) or vehicle (saline) was microinjected into the corpus callosum at a rate of 0.5 $\mu \mathrm{L} /$ min using a microinjection pump (PDH 2000; Harvard Apparatus, Holliston, MA), with the following coordinates: $0.1 \mathrm{~mm}$ posterior from bregma, $1.8 \mathrm{~mm}$ lateral from the sagittal suture, and $3.2 \mathrm{~mm}$ below the dura mater.

\section{Measurement of Infarct Volume}

Rats were anesthetized with chloral hydrate and decapitated at 1 day after MCAO. Coronal sections of brain (2 $\mathrm{mm}$ ) were stained with $2 \%$ triphenyltetrazolium chloride (Sigma-Aldrich) at $37^{\circ} \mathrm{C}$ for 30 minutes, fixed with $4 \%$ paraformaldehyde $(\mathrm{pH} 7.4)$ in $0.1 \mathrm{~mol} / \mathrm{L}$ phosphate buffer for 1 day, and subsequently cryoprotected in phosphate buffer containing $30 \%$ sucrose at $4^{\circ} \mathrm{C}$ for 2 days. The cross-sectional area of infarction between the bregma levels of +4 $\mathrm{mm}$ (anterior) and $-6 \mathrm{~mm}$ (posterior) were determined with Optimas version 5.1 image analysis software (Bioscan, 
Edmonds, WA). Brain infarct size was measured manually by outlining the margins of infarct areas. The total infarction volume was integrated from six chosen sections, expressed as a percentage of the total brain volume, and compensated for brain edema, as described previously. ${ }^{28,29}$ Cerebral edema was determined in a double-blind manner by the percent increase of the ipsilateral/contralateral hemisphere area: \% edema volume = [(ipsilateral volume - contralateral volume)/contralateral volume] $\times 100$. Thereafter, the tissues were frozen, cut into 10- or 30- $\mu \mathrm{m}$ coronal sections on a Leica 3050 cryostat (Leica, Nussloch, Germany) and stored at $-20^{\circ} \mathrm{C}$.

\section{Immunohistochemistry}

The brain sections were quenched with $0.3 \%$ hydroperoxide, blocked with 10\% normal horse serum, and then stained with mouse anti-ED1 antibody overnight at room temperature (diluted 1:200; Serotec, Oxford, UK). After further staining with biotinylated anti-mouse IgG (Vector Laboratories, Burlingame, CA) and peroxidase-conjugated streptavidin (diluted 1:200; Vector Laboratories), the antigens were visualized with 5 minutes of incubation at $37^{\circ} \mathrm{C}$ in $0.1 \mathrm{~mol} / \mathrm{L}$ phosphate buffer containing $0.02 \%$ 3,3-diaminobenzidine and $0.0045 \%$ hydrogen peroxide (ABC method). The number of ED1-positive cells was manually counted in 10 grids $\left(0.1 \mathrm{~mm}^{2} / \mathrm{grid}\right)$ using a DMC2 digital microscope camera (Polaroid, Minnetonka, $M N$ ), and averaged from three to five adjacent sections.

\section{Microglial Cell Culture}

Pure microglial cells were prepared from primary mixed glial cell culture. Cerebral cortices from neonatal SpragueDawley rats ( 1 to 2 days old) were triturated to single cells. They were then plated into poly-D-lysine $(1 \mu \mathrm{g} / \mathrm{mL}$; SigmaAldrich) coated $75-\mathrm{cm}^{2}$ T-flasks and maintained in modified Eagle's medium (MEM) containing 10\% fetal bovine serum. At 7 or 8 days after plating, microglia were detached from the flasks by mild shaking $\left(37^{\circ} \mathrm{C}, 2\right.$ minutes at $\left.200 / \mathrm{min}\right)$ and plated onto the experimental plates. After 6 hours, microglia were replaced with serum-free MEM and were used for experiments after an overnight.

\section{Enzyme-Linked Immunosorbent Assay}

The concentrations of IL-1 $\beta$, TNF- $\alpha$, and MCP- 1 were measured by enzyme-linked immunosorbent assay using monoclonal antibodies according to the manufacturer's procedures (KOMA Biotech, Seoul, Korea).

\section{Chemotaxis}

Microphotographs of migrating microglial cells in the live cell chamber (Live Cell Instrument, Seoul, Korea) were monitored with inverted confocal microscopy system (Leica DMIRE2, TLC_SP2) and differential interference contrast transmission image programs (Leica, Ver. 2.5). Fifteen minutes after LJ529 was applied by micromanipulator ( $\mathrm{Na}$ - rishige, Japan), the MCP-1 gradient (100 ng/mL; BD Pharmingen, San Jose, CA) was generated using a Harvard Apparatus microinjection device $(0.1 \mu \mathrm{L} / \mathrm{min}$; PHD 2000 programmable). MRS1523 (1 $\mu \mathrm{mol} / \mathrm{L})$ or SCH58261 (100 $\mathrm{nmol} / \mathrm{L}$ ) was applied to the cells for 20 minutes before treatment with MCP-1. For quantitative analysis, MCP-1 was placed in the bottom chamber of a chemotaxis chamber (Neuro Probe, Cabin John, MD) and microglia $\left(5 \times 10^{4}\right.$ cells $/ \mathrm{mL}$ in serum-free MEM ) in the upper chamber were allowed to migrate to the bottom part for 2 hours, through membrane pore ( $8 \mathrm{~mm}^{2}$ filter area; Neuro Probe). Migrated cells on the bottom-side filter were stained for nuclei with Harris's hematoxylin and then counted. The movement or morphological change of microglia was recorded in video for 20 minutes starting from the application of MCP-1 (see Supplemental Videos S1-S4 at http://ajp.amjpathol.org).

\section{Immunocytochemistry}

After stimulation with gradient MCP-1 for 5 minutes, microglia were fixed and stained with primary antibodies against Rac, Cdc42, and Rho (diluted 1:500, 1:250 and 1:250, respectively; Millipore-Upstate Biotechnology, Lake Placid, NY) and Alexa Fluor 488-phalloidin (diluted 1:2000; Molecular Probes, Carlsbad, CA) for filamentous actin.

\section{Activation of Rho GTPase}

Active forms of GTPase (GTP-bound forms) were measured by pull-down kits for Rho GTPases (Millipore-Upstate). Briefly, microglia were stimulated with MCP-1 (100 ng/mL), then lysed with kit-supplied buffer, and centrifuged at $14,000 \times g$ for 5 minutes. Equal amounts of the supernatant fractions obtained were incubated with either PAK-1 PBDagarose (which binds Rac-GTP or Cdc42-GTP) or rhotekin RBD-agarose (which binds Rho-GTP) for 1 hour at $4^{\circ} \mathrm{C}$, followed by washing three times. Proteins bound to the beads were eluted in Laemmli sample buffer and subjected to Western blot analysis using mouse monoclonal antibodies specific to Rac, Cdc42, and Rho, respectively.

\section{Cortical Neuronal Culture}

Cortical neurons $\left(5 \times 10^{5}\right.$ cells $\left./ \mathrm{mL}\right)$ were prepared from fetal rats (17 to 18 embryonic days old) and plated on poly-D-lysine $(100 \mu \mathrm{g} / \mathrm{mL}) /$ laminin $(4 \mu \mathrm{g} / \mathrm{mL})$-precoated plates using 10\% fetal bovine serum-DMEM with $2 \mathrm{mmol} / \mathrm{L}$ glutamine, $100 \mathrm{U} / \mathrm{mL}$ penicillin, and $100 \mu \mathrm{g} / \mathrm{mL}$ streptomycin. At 3 days after culture, $5 \mu \mathrm{mol} / \mathrm{L}$ cytosine arabinoside was applied to block non-neuronal cell division. The medium was then replaced twice a week. Experiments were performed at 14 to 16 days in vitro.

\section{Oxygen-Glucose Deprivation (OGD) and Reoxygenation and Excitotoxicity}

For in vitro hypoxic-ischemic insult, cultured neurons were placed in an anaerobic chamber (partial pressure of oxygen $<2 \mathrm{mmHg}$ ) at $37^{\circ} \mathrm{C}$ for 1 hour. OGD was discontinued by replacing with oxygenated DMEM containing $25 \mathrm{mmo} / \mathrm{L}$ 

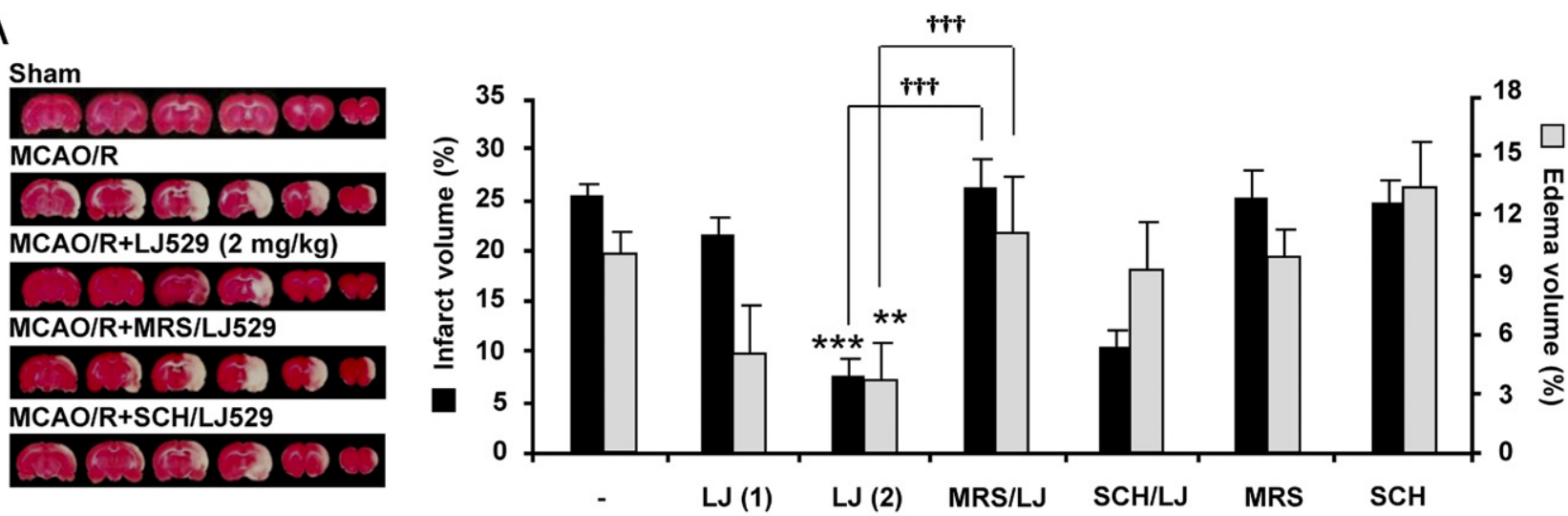

B

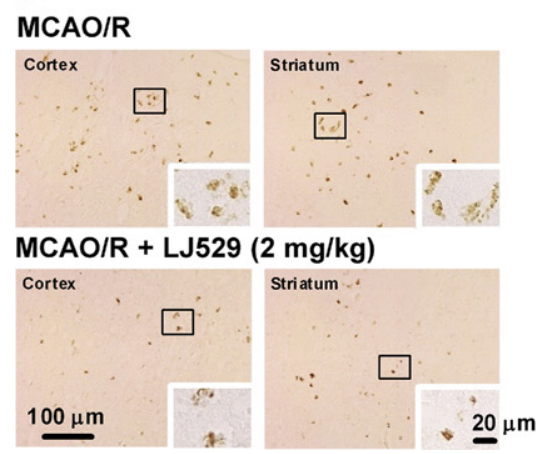

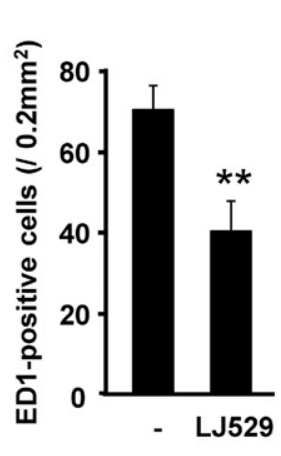

C

\section{LPS}

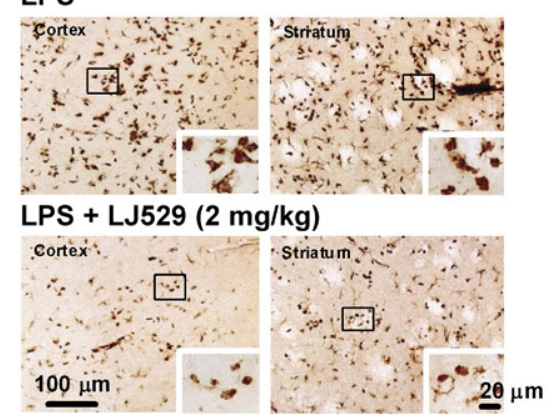

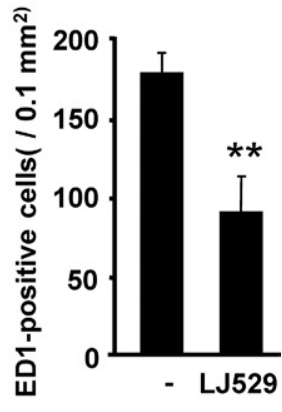

Figure 1. LJ529 reduces cerebral infarct volume and ED-1 immunoreactivity. A: Cerebral infarct and edema volume. Rats were exposed to MCAO for 1.5 hours and subsequent reperfusion (R) for 24 hours. LJ529 [1 or $2 \mathrm{mg} / \mathrm{kg}$, respectively marked as LJ(1) or LJ(2)] was administered intraperitoneally twice, at 2 and 7 hours after onset of ischemia, in the absence or presence of either MRS1523 (1 mg/kg) or SCH58261 (70 $\mu \mathrm{g} / \mathrm{kg}$ ). Representative tetrazolium chloride staining images (left) of brain sections (for LJ529, $2 \mathrm{mg} / \mathrm{kg}$, twice). Quantitative data (right) are reported as means \pm SEM. $n=4$ to 14 per group. ${ }^{* * *} P<0.01$ and ${ }^{* * * * * *} P<0.001$ versus MCAO/R group; ${ }^{*} P<0.001$ versus LJ 529 (2 mg/kg, twice) group [LJ (2)]. B and C: ED-1 immunoreactivity. Brain tissues were stained with anti-ED-1 antibody at 24 hours after MCAO/R (B) or LPS injection into corpus callosum (C). ED-1-postive cells per $0.1 \mathrm{~mm}^{2}$ were counted in the cortex or striatum of ipsilateral regions. $n=8$ per group. ${ }^{* * *} P<0.01$ versus MCAO/R or LPS-treated group.

glucose and returning the cells to normoxic conditions. Control cells, not exposed to OGD, were maintained in DMEM containing glucose $(25 \mathrm{mmol} / \mathrm{L})$, aerated with an aerobic gas mix (95\% air, 5\% CO $\mathrm{CO}_{2}$ ). LJ529 was applied immediately after reoxygenation. To evoke excitotoxicity, neurons were treated with $100 \mu \mathrm{mol} / L$ NMDA for 10 minutes in the presence or absence of LJ529.

\section{Assessment of Cell Injury or Death}

Cell injury or death was assessed by the amount of lactate dehydrogenase released into the bathing medium using a diagnostic kit (Sigma-Aldrich) and expressed as a percentage of total lactate dehydrogenase, which was measured in sister cultures frozen and thawed after the experiments. ${ }^{30}$

\section{Measurement of Plasma Membrane Potential}

Plasma membrane potential was monitored by using bisoxonol fluorescent dye [(bis-[1,3-diethyl-thio-barbiturate]-trimethineoxonol) $\left(\mathrm{DiBAC}_{4}(3)\right]$ (excitation at $540 \mathrm{~nm}$; emission at $565 \mathrm{~nm}$ ); the increase in intensity indicates the membrane depolarization. ${ }^{31}$ Neurons were preincubated with $5 \mu \mathrm{mol} / \mathrm{L}$ $\mathrm{DiBAC}_{4}(3)$ for 10 minutes before LJ529 treatment. Immediately after cells were exposed to $100 \mu \mathrm{mol} / \mathrm{L}$ NMDA, timelapse fluorescence intensity (excitation at 540 nm; emission at $565 \mathrm{~nm}$ ) was measured with a fluorescence plate reader (SpectraMAX GeminiEM; Molecular Devices, Sunnyvale, CA) and compensated with autofluorescence [ie, fluorescence in non-loaded cells with $\left.\mathrm{DiBAC}_{4}(3)\right]$.

\section{Measurement of Antioxidant Activities}

For direct scavenging activity of LJ529, peroxynitrite donor 3-morpholinosydnonimine ( $\mathrm{SIN}-1,200 \mu \mathrm{mol} / \mathrm{L}$ ) or $\mathrm{H}_{2} \mathrm{O}_{2}$ (1 $\mathrm{mmol} / \mathrm{L})$ was added to Earle's balanced salt solution buffer containing $10 \mu \mathrm{mol} / \mathrm{L}$ dihydrorhodamine 123 in the absence and presence of LJ529. After 10 minutes at room temperature, rhodamine 123 fluorescence (excitation at $490 \mathrm{~nm}$; emission at $530 \mathrm{~nm}$ ) was measured with a fluorescence microplate reader (SpectraMAX GeminiEM; Molecular Devices). To measure oxidant levels, $30 \mu \mathrm{mol} / \mathrm{L}$ dichlorodihydro-fluorescein diacetate $\left(\mathrm{H}_{2} \mathrm{DCF}-\mathrm{DA}\right)$ was applied for 10 minutes in Earle's balanced salt solution buffer containing $0.1 \%$ bovine serum albumin and $2.5 \mathrm{mmol} / \mathrm{L}$ probenecid after LPS treatment for 18 hours. After washing out $\mathrm{H}_{2}$ DCF-DA supernatant, fluorescence was measured (excitation at $488 \mathrm{~nm}$; emission at $525 \mathrm{~nm}$ ). Catalase and superoxide dismutase were added 30 minutes before measurement to remove hydrogen peroxide or superoxide, respectively. For the measurement of nitric oxide (NO) production, nitrite levels in the supernatants were determined by the Griess test, as described previously. ${ }^{32}$ 
A
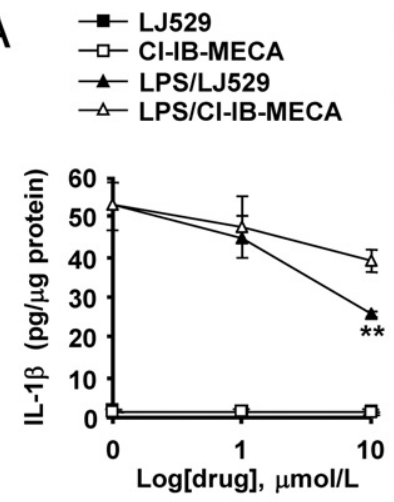

B

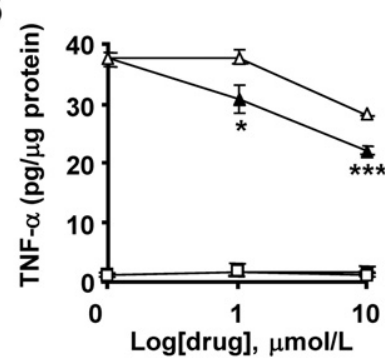

C

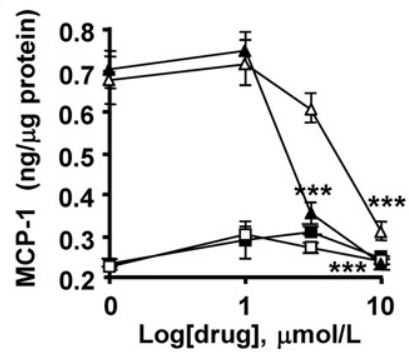

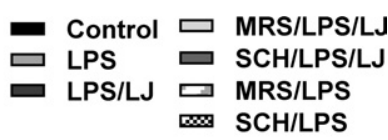
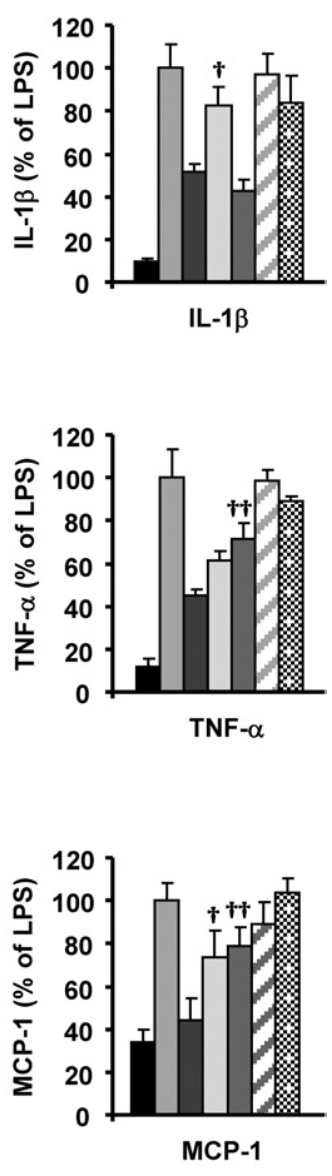

Figure 2. LJ529 decreases release of inflammatory cytokines/chemokines. Microglial cells were stimulated with LPS in the absence or presence of LJ529 or Cl-IB-MECA. A-C, left: Six hours later, the amounts of IL-1 $\beta$ (A), TNF- $\alpha$ (B), or MCP-1 (C) released into bathing medium were measured using enzyme-linked immunosorbent assay kits. $n=4$ per group. ${ }^{*} P<0.05$, ${ }^{* * *} P<$ 0.01 , and ${ }^{* * * * *} P<0.001$, untreated versus drug-treated groups. A-C, right: To measure effects of $\mathrm{A} 3 \mathrm{~A}$ or $\mathrm{A} 2 \mathrm{AAR}$ antagonists, microglial cells were pretreated with either MRS1523 $(1 \mu \mathrm{mol} / \mathrm{L})$ or SCH58261 $(100 \mathrm{nmol} / \mathrm{L})$ for 30 minutes and then stimulated with LPS in the absence or presence of 10 $\mu \mathrm{mol} / \mathrm{L} \mathrm{LJ} 529 . n=3$ per group. ${ }^{\dagger} P<0.05$ and ${ }^{\dagger} P<0.01$ versus corresponding LPS/LJ529-treated groups.

\section{Statistical Analysis}

Data were analyzed for statistical significance by one-way analysis of variance followed by Scheffé's test for multiple comparisons. Data are reported as means \pm SEM (for in vivo infarction and edema volume) or SD.

\section{Results}

\section{Postischemic Treatment of LJ529 Reduces Cerebral Ischemic Infarct and Inhibits Infiltration of Activated Microglia/Monocytes into Ischemic Lesions}

In double-blinded, randomized experiments in rats, postischemic treatment of LJ529 (2 mg/kg, twice) reduced ce-

rebral ischemic infarction and edema by $69.9 \pm 6.4 \%$ and $63.1 \pm 18.4 \%$, respectively (Figure $1 A$ ). This anti-ischemic effect of LJ529 was abolished by the A3AR antagonist MRS1523. Among adenosine receptor subtypes, A2AAR has also been associated with the modulation of cerebral hypoxic/ischemic injury. ${ }^{33}$ In the present study, however, the A2AAR antagonist SCH58261 did not alter the antiischemic effect of LJ529. Neither MRS1523 nor SCH58261 alone significantly reduced infarction size and edema (Figure 1A). LJ529 significantly reduced the infiltration/migration of ED-1-immunopositive microglia/monocytes into ischemic cortical and striatal lesions (Figure 1B). We previously found that microinjection of LPS into rat corpus callosum highly increased the infiltration of activated microglia/monocytes into the ipsilateral hemisphere. ${ }^{34}$ LJ529 also inhibited LPSstimulated infiltration/migration of microglia/monocytes (Figure 1C). LJ529 treatment itself did not alter physiological parameters such as mean arterial pressure, $\mathrm{pH}$, arterial partial $\mathrm{CO}_{2}$ and $\mathrm{O}_{2}$ pressures, and blood glucose concentrations in both normal and ischemia-induced rats (data not shown).

\section{LJ529 Inhibits LPS-Induced IL-1 $\beta$, TNF- $\alpha$, and MCP-1 Release in Microglia}

A3AR agonists have been reported to inhibit LPS-induced cytokine/chemokine production in microglial or macrophageal cells. ${ }^{35-38}$ We therefore examined the effect of LJ529 on the cytokine/chemokine release in activated microglia of rats. LJ529 significantly inhibited the release of IL-1 $\beta$, TNF- $\alpha$, and MCP-1 in LPS-treated microglia in vitro (Figure 2). As expected from its higher potency and selectivity to A3AR compared with Cl-IB-MECA, ${ }^{21}$ LJ529 was more potent than Cl-IB-MECA in inhibiting the release of all cytokines/chemokines tested (Figure 2). However, because LJ529 inhibited the cytokine/chemokine release only at micromolar concentrations, LJ529 might also activate other AR subtypes, such as A2AAR. Although An A3AR antagonist MRS 1523 diminished the inhibitory effect of LJ529 on $\mathrm{IL}-1 \beta$ and MCP- 1 release, an A2AAR antagonist SCH58261 reduced the effect of LJ529 on TNF- $\alpha$ and MCP-1 release (Figure 2). These findings suggest that the observed effect of micromolar concentrations of LJ529 on cytokine/chemokine release may be mediated via activation of A2AAR, as well as A3AR.

\section{LJ529 Inhibits MCP-1-Induced Microglial Migration}

Because LJ529 reduced the infiltration/migration of ED1-positive cells both in ischemic and LPS-stimulated brain lesions (Figure 1), we examined whether LJ529 directly inhibits chemoattractant-induced migration of microglia/monocytes. Both time-lapse confocal microscopy and chemotaxis assay revealed that LJ529 inhibited MCP-1 (100 ng/mL)-induced migration of microglial cells with higher potency than CI-IB-MECA $\left(\mathrm{IC}_{50}=\sim 1 \mathrm{nmol} / \mathrm{L}\right)$ (Figure 3). Similar results were also obtained with monocytes (data not shown). Of note, the concentration of LJ529 to inhibit the chemotaxis of activated microglia 
A

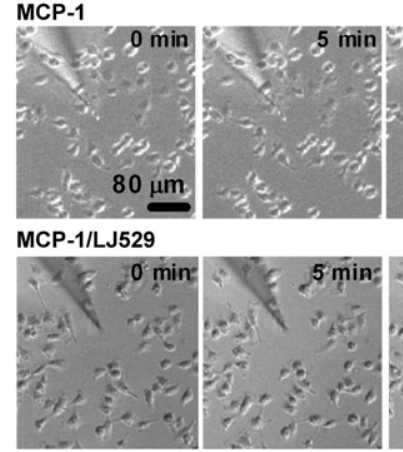

C

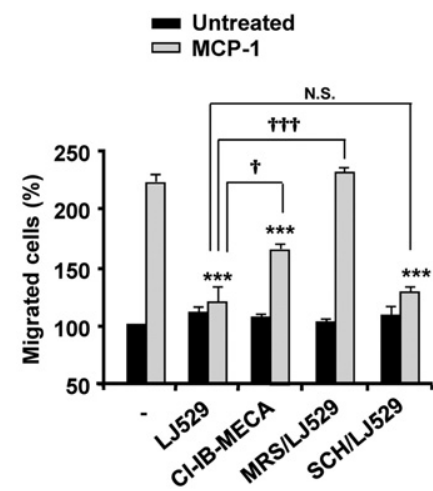

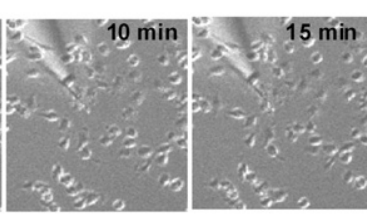
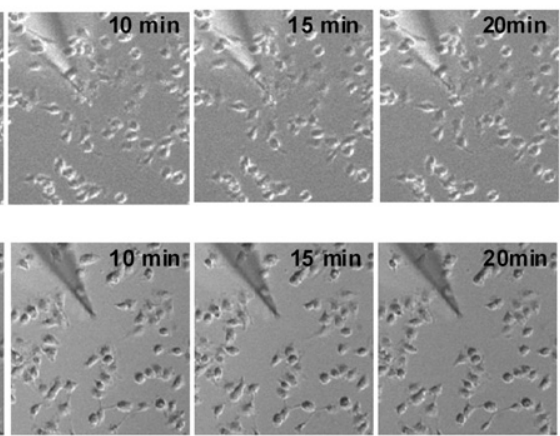

D
B

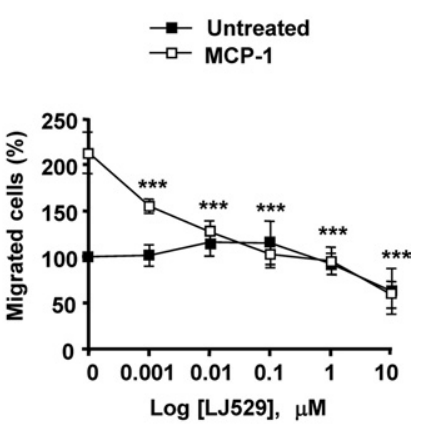

Figure 3. Inhibition of MCP-1-induced microglial chemotaxis by LJ529. A: Time-lapse microscopy (see Supplemental Videos S1 and S2 at http://ajp.amjpathol. org). Microglia were pretreated with $100 \mathrm{nmol} / \mathrm{L} \mathrm{LJ} 529$ or vehicle for 15 minutes and then stimulated with $100 \mathrm{ng} / \mathrm{mL} \mathrm{MCP-1} \mathrm{for} 20 \mathrm{minutes}$. B: MCP-1-evoked migration of microglia was quantified using a chemotaxis chamber. $n=6$. ${ }^{* * * *} P<0.001$ versus MCP-1-treated microglia in the absence of LJ529. C: Microglia were pretreated with MRS1523 (1 $\mu \mathrm{mol} / \mathrm{L})$ or SCH58261 (100 nmol/L) for 20 minutes and the effect of either $\mathrm{LJ} 529$ (10 nmol/L) or Cl-IB-MECA (10 nmol/L) on chemotactic movement was determined in the absence or presence of MRS1523 or SCH58261. $n=4 .{ }^{* * * *} P<0.001$ versus MCP-1-treated group. ${ }^{\dagger} P<0.05$ and ${ }_{t+} P<0.001$ versus MCP-1/LJ529-treated group. D: Time-lapse microscopy (see Supplemental Videos S3 and S4 at http://ajp.amjpathol.org). Arrows indicate protruding edges toward tip, and arrowheads indicate retracting edges. $100 \mathrm{nmol} / \mathrm{L}$ LJ529 inhibited chemotactic sensing and movement to the point of MCP-1 source. $n=3$

(nanomolar ranges) was approximately 1000-fold lower than those for cytokine/chemokine release (micromolar ranges). This finding suggests that the inhibitory effect of LJ529 on microglial chemotaxis may not be a secondary effect through reduced cytokine/chemokine release, but rather a direct effect on cellular migration machinery, which regulates cellular motility and/or responses on chemotactic molecules. Moreover, this effect was abolished by the A3AR antagonist MRS1523 (Figure 3C) or MRS1191 (100 nmol/L, data not shown), but not by the A2AAR antagonist SCH58261 (Figure 3C), suggesting that the inhibitory effect of LJ529 on the chemotaxis is selectively mediated via A3AR.

Directed migration is a consecutive and cycling process of multiple steps: protrusion at the leading edge, adhesion of the protrusive edge, contraction of the cytoplasmic actomyosin, and final release from contact sites at the tail of the cell. ${ }^{39-41}$ Thus, cell migration is inevitably accompanied with changes in cytoskeleton. In careful morphological examination of the migration step, we found that LJ529 completely blocked the extended protrusion at the leading edge toward the center of MCP-1 gradient and the retraction of the trailing edge of micro- glial cells (Figure 3, A and D; see also Supplemental Videos S1-S4 at http://ajp.amjpathol.org).

\section{LJ529 Disturbs MCP-1-Induced Spatial Localization of Rho GTPases (Rac, Cdc42, and Rho) in Microglia}

The directed migration of immune cells such as monocytes is governed by the chemokine-evoked activation and polarized expression of Rho GTPases. ${ }^{42,43}$ The Rho GTPases Rac, Cdc42, and Rho play an important role in the regulation of actin organization in cell motility and movement. In microglia, MCP-1 rapidly induced the activation of Rac, Cdc42, and Rho proteins, which were inhibited by LJ529 (Figure 4, A-C). MCP-1 induced polarized expressions of Rac and Cdc42, which were colocalized with filamentous actin at the leading edge, whereas Rho was excluded from lamellipodia and preferentially distributed in a direction opposite to cell migration (Figure 4D). LJ529 abolished these spatial localizations of Rac, Cdc42, and Rho, possibly leading to the loss of direction in microglial cell migration (Figure 4D). 
A
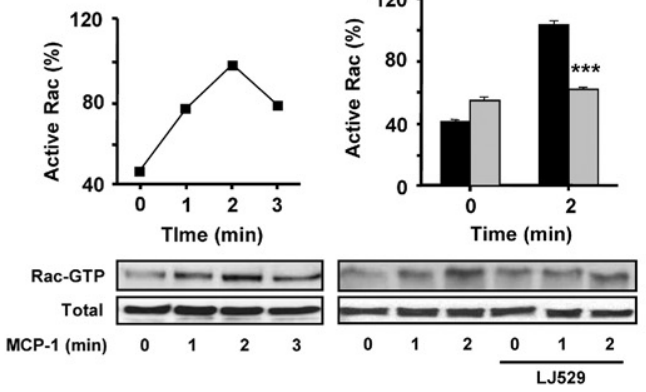

B

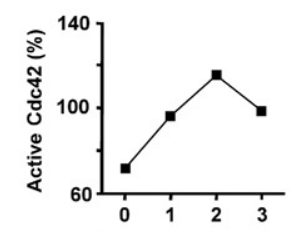

Cdc42-GTP

Total

C
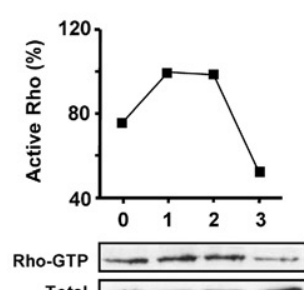

Total
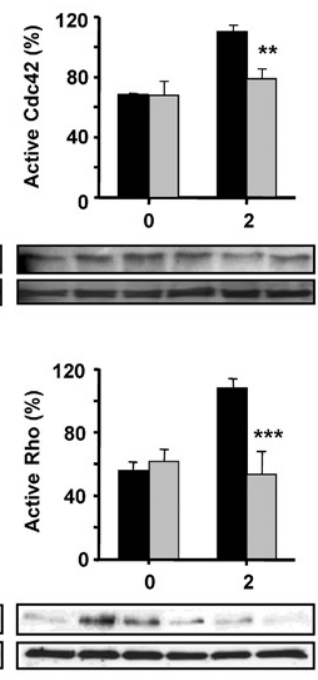

D Control
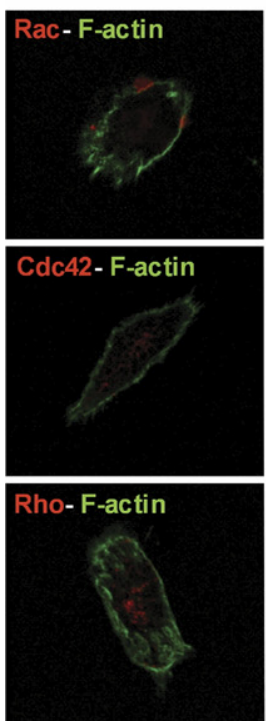

Figure 4. Inhibition of activity and expression of Rho GTPases. A-C: Microglia were pretreated with $100 \mathrm{nmol} / \mathrm{L} \mathrm{LJ} 529$ for 15 minutes and then stimulated with $100 \mathrm{ng} / \mathrm{mL}$ MCP-1 for the indicated times. Active forms of each Rho GTPase were pulled down from microglial lysates by using a pull-down kit and then subjected to Western blotting analysis. $n=4$ per group. ${ }^{* *} P<0.01$ and ${ }^{* * * *} P<0.001$ versus untreated group. D: Double staining of GTPases (Red) and filamentous actin (Green) in migrating cells. Microglia were stimulated with gradient MCP-1 for 5 minutes in the presence or absence of $100 \mathrm{nmol} / \mathrm{L} \mathrm{LJ} 529$ and then fixed for immunocytochemistry. Asterisks indicate the tip point of the micropipette containing $100 \mathrm{ng} / \mathrm{mL}$ MCP-1. Data are representative of four separate experiments.

\section{LJ529 Does Not Prevent NMDA-Induced or OGD-Reoxygenation-Induced Neurotoxicity in Cortical Neurons}

Excitotoxicity is one of critical factors in ischemia-evoked neuronal death, especially in the early stage of cerebral ischemia. ${ }^{1}$ We found that neuronal cell death induced by NMDA or OGD/reoxygenation was not inhibited by LJ529 in cortical neuron cultures (Figure 5, A and B). Furthermore, NMDA-induced neuronal death and plasma membrane potential depolarization also were not inhibited by LJ529 (Figure 6, B and C), and LJ529 did not constrain the increase of DCF fluorescence level in cultured neuronal cells treated with NMDA or OGD/reoxygenation (data not shown).

\section{LJ529 Neither Directly Scavenges Reactive Oxygen Species nor Reduces Reactive Oxygen Species Release in LPS-Stimulated Microglia}

Activated inflammatory cells produce reactive oxygen species (ROS), as well as inflammatory cytokines. ${ }^{44,45}$ We found that LJ529 did not directly scavenge hydrogen peroxide and peroxynitrite (Figure 6A). Therefore, to further examine the effect of LJ529 on ROS production in activated microglial cells, we measured the levels of ROS and NO by using DCF-DA and Griess reagent, respectively. Although activation of A3AR was previously reported to suppress the superoxide production in mouse bone marrow neutrophils, ${ }^{46}$ LJ529 did not reduce the production of ROS and NO in LPS-treated microglial cells (Figure 6, B and C).

\section{Discussion}

The recent recognition that cerebral stroke and other ischemic injury are manifestations of chronic progressive inflammation has had great influence on the development of therapeutic and preventative strategies. ${ }^{7,47}$ In most previous studies, A3AR agonists were administered before or immediately after stroke. ${ }^{15,17,18}$ The present study is the first to demonstrate anti-ischemic protection achieved by postischemic treatment (ie, at 2 and 7 hours after the onset of ischemia) of the A3AR agonist LJ529. The A3AR antagonist abolished this anti-ischemic effect of LJ529 (Figure 1). Excitotoxicity and oxidative stress are major factors causing neuronal cell death in the early stage of cerebral ischemic insults ${ }^{1,48}$ However, the antiischemic effect of LJ529 appears not to be related with blockade of excitotoxicity and oxidative stress (Figures 5 and 6). Rather, LJ529 reduces cerebral ischemic injury through activation of the A3AR, potentially via suppression of postischemic inflammatory responses such as infiltration/migration of inflammatory cells.

Neuroinflammatory mechanisms are activated after an ischemic insult by excitotoxicity and oxidative stress and play a pivotal role in prolonged brain damage in ischemia. ${ }^{1,7,45}$ A rapid activation of resident microglial cells and infiltration of peripheral inflammatory monocytes has 
A

$$
\text { ש Control }
$$

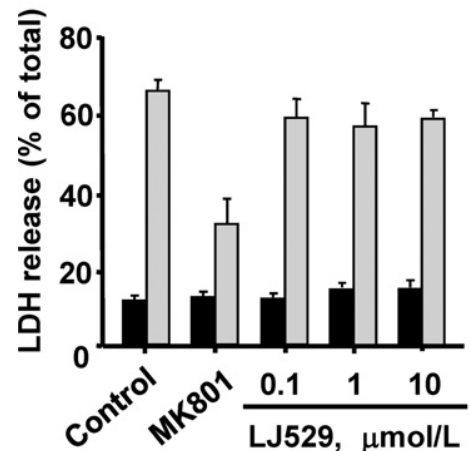

B

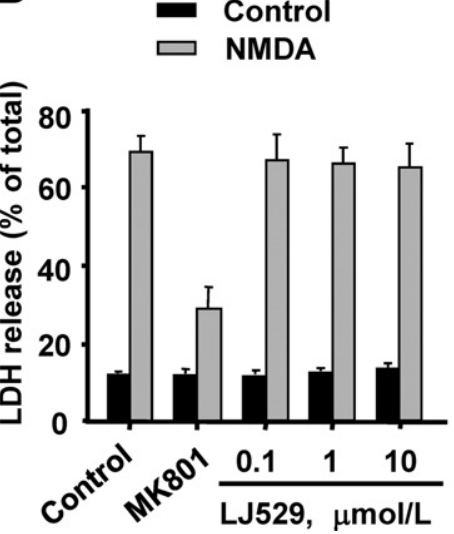

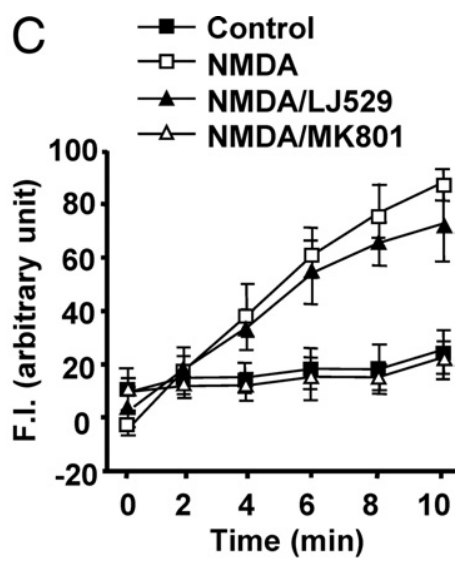

Figure 5. No blockade by LJ529 of neuronal injury evoked by OGD/R or NMDA. A and B: Although neuronal cell death induced by OGD/reoxygenation or NMDA was significantly inhibited by MK-801, an NMDA receptor blocker, it was not inhibited by LJ529. Cortical neurons were exposed to OGD for 1 hour $(\mathbf{A})$ or $100 \mu \mathrm{mol} / \mathrm{L}$ NMDA for 10 minutes $(\mathbf{B})$ in the absence or presence of LJ529. Another 6 hours later, lactate dehydrogenase released into bathing medium was determined. C: Depolarization of plasma membrane potential. NMDA-induced plasma membrane potential depolarization was not inhibited by LJ529. Cells were loaded with $\mathrm{DiBAC}_{4}(3)$ and then $\mathrm{LJ} 529$ was added. Ten minutes later, cells were exposed to $100 \mu \mathrm{mol} / \mathrm{L}$ NMDA and the fluorescence intensity was measured. Fluorescence intensity values were corrected by subtracting autofluorescence [ie, fluorescence in cells not loaded with $\mathrm{DiBAC}(3)$ ]. $n=4$ at each time point

been shown to modulate the extent of ischemic brain damage. ${ }^{1,45}$ We also found that LPS-activated microglia and monocytes accelerated and aggravated cerebral ischemic injury, ${ }^{34}$ and that depletion of peripheral leukocytes by $\gamma$-irradiation before ischemia reduced the cerebral infarction caused by MCAO/R (unpublished data). In the present study, LJ529 was found to inhibit the infiltration/migration of microglia/monocytes induced by MCAO/ $\mathrm{R}$ or injection of LPS into the corpus callosum (Figure 1). It is quite reasonable, therefore, to confirmed that LJ529 reduces postischemic cerebral injury via suppression of infiltration/migration of inflammatory cells and their immune responses.

Many earlier studies have demonstrated that activation of $A 3 A R$ reduces the production/release of proinflammatory cytokines in activated inflammatory cells, ${ }^{12,36,38,49,50}$ which were widely accepted as a key detrimental factor in cerebral ischemic injury. ${ }^{47}$ The A3AR agonist CI-IBMECA inhibits LPS-induced TNF- $\alpha$ production in vivo, decreasing its effect in A3AR knockout mice. ${ }^{51}$ Another A3AR agonist, IB-MECA, has been shown to suppress the production of IL-12 and IFN- $\gamma$, and to reduce lethality in endotoxemic mice. ${ }^{12}$ IB-MECA also suppresses LPSinduced production of either TNF- $\alpha^{49}$ or the chemokine macrophage inflammatory protein (MIP)- $1 \alpha^{12}$ in macrophageal RAW 264.7 cells. Similarly, activation of adenosine A3 receptor suppresses LPS-induced TNF- $\alpha$ production in murine BV2 microglial cells. ${ }^{36}$

Consistent with previous studies, we have demonstrated that LJ529 significantly reduced the release of $\mathrm{IL}-1 \beta$, TNF- $\alpha$, and MCP- 1 in LPS-treated microglial cells (Figure 2). Notably, however, the $\mathrm{IC}_{50}$ values of LJ529 for
A
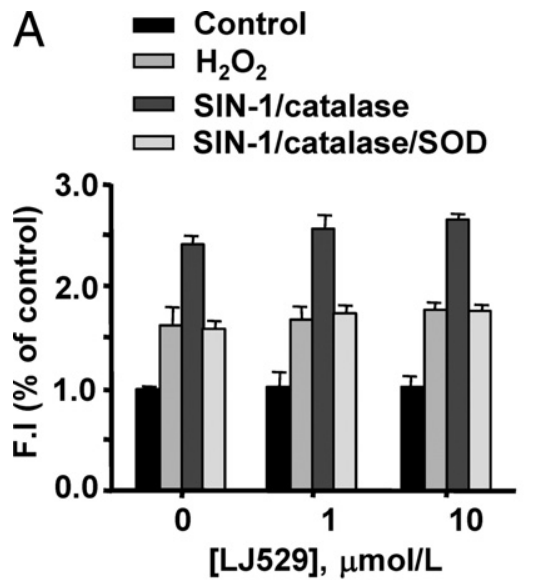

B

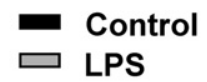

LPS/catalase $\square$ LPS/catalase/SOD

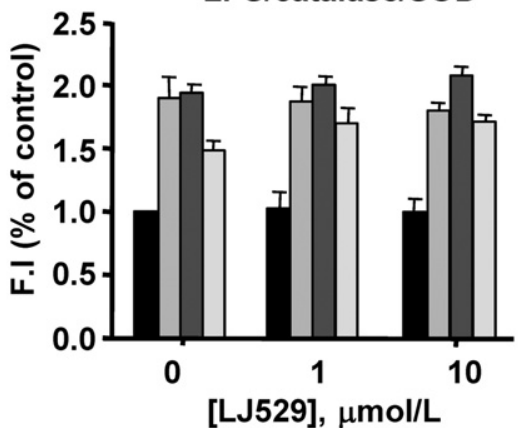

C
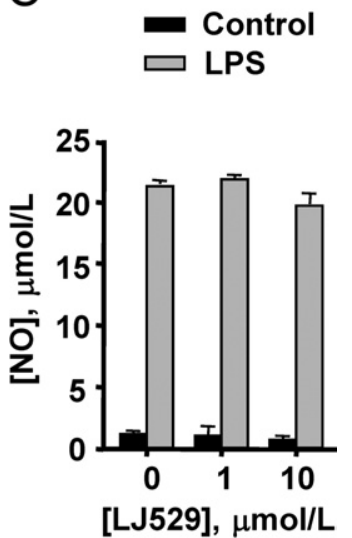

Figure 6. ROS scavenging effect or inhibitory effect of ROS release by LJ529. A: Dihydrorhodamine 123 fluorescence. LJ529 did not directly scavenge hydrogen peroxide or peroxynitrite. The fluorescence intensity of the control cells was assigned to $1 . n=3$ per group. B: DCF fluorescence. LJ529 did not reduce the release of ROS in activated microglial cells. DCF fluorescence was measured after LPS treatment for 18 hours in the presence or absence of LJ529. Catalase or superoxide dismutase (SOD) was applied for 30 minutes before fluorescence measurement. $n=4$ per group. C: Nitrite assay. LJ529 did not reduce the release of NO in LPS-treated microglial cells. The amount of nitrite was obtained from the supernatant of microglia treated with LPS for 18 hours in the presence or absence of LJ529. $n=4$ per group. 
the inhibition of cytokine/chemokine release were $\sim 10$ $\mu \mathrm{mol} / \mathrm{L}$. Compared with the nanomolar level of $K_{\mathrm{i}}$ values for A3AR, ${ }^{19-21}$ these relatively high $I_{50}$ values of $L J 529$ and also of CI-IB-MECA in the present study suggest that A3AR may not play a major role in LPS-induced cytokine release in microglia. Because the potency and efficacy of A3AR agonists depend on the quantities of receptors and second messenger profiles present in a certain cell type, ${ }^{52}$ it is also possible that the $I_{50}$ values of A3AR agonists are cell type-dependent (eg, at micromolar levels particularly in microglia), as shown in the present study and by others. ${ }^{36}$ Also, the effect of adenosine receptor agonists on cytokine release has been shown to be subject to the specific Toll-like receptor used for immune stimulation in a cell-type-dependent manner, ${ }^{53}$ and Toll-like receptor activation by LPS induces an up-regulation of A2AAR and a down-regulation of A3AR in primary rhesus monkey microglia. ${ }^{54}$ This high level of LJ529 concentration in blood might not be obtained in vivo by dual injection of LJ529 (2 mg/kg each), as in the present study. A pharmacokinetic analysis showed that the peak plasma concentration of LJ529 was below micromolar level (unpublished data). Moreover, although the effect of LJ529 on cytokine/chemokine release was shown to be diminished by both A3AR and A2AAR antagonists (Figure 3), only the A3AR antagonist (and not the A2AAR antagonist) blocked the anti-ischemic effect of LJ529 in vivo (Figure 1). Thus, attenuation of cerebral infarction by LJ529 may not be fully attributed to the decreased production of inflammatory cytokines.

LJ529 directly inhibited MCP-1-induced microglial chemotaxis through A3AR (Figure 3). This result is consistent with previous studies in human lung eosinophils ${ }^{55}$ and mouse bone marrow neutrophils, ${ }^{14,46}$ showing that selective activation of the A3AR regulates the chemotaxis of inflammatory cells. Because L529 exerts the anti-chemotactic effect at nanomolar concentrations, we further examined the effect of an A3AR agonist on cellular chemotactic machinery, especially the Rho family of small GTPases, as a putative mechanism underlying the anti-ischemic effect of LJ529. The Rho GTPases are expressed in inflammatory cells, and their inhibitors are known to prevent the migration of inflammatory monocytes or leukocytes into brain and to attenuate the inflammatory process in multiple sclerosis animal models. ${ }^{42,56}$

For directed cell migration, cells have to be polarized through the expression cytoskelectal change and the activation and polarized expression of Rho GTPases is known to play a key role in regulating the polarized actin cytoskeleton that organizes the membrane protrusions and focal adhesions. ${ }^{39-43}$ Forward protrusion to move (lamellipodia or filopodia) is associated with actin polymerization, which is coupled to an actin-myosin II-mediated contraction at the posterior of the cell (uropod). ${ }^{57-59}$ Although the A3AR agonist $\mathrm{Cl}$ IB-MECA has been reported to induce Rho-mediated stress fibers in human astroglioma cells, ${ }^{60}$ the relationship between A3AR agonist and Rho GTPases in immune cells remains obscure. Moreover, because microglia do not possess stress fibers, ${ }^{61}$ Rho GTPases cannot act on stress fibers in these cells. Instead, we demonstrated for the first time in the present study that LJ529 inhibits the activity and polarized expression of Rac, Cdc42, and Rho in microglia (Figure 4), possibly inhibiting actin polarity and cytoskeletal change and thus leading to decreased MCP-1-induced chemotaxis and migration. Further studies using a constitutively active form or an RNA interference of Rho GTPases in combination with LJ529 may confirm our assumptions in microglia.

In cultured cortical neurons, we found that postischemic treatment with LJ529 did not prevent OGD/reoxygenation-evoked neurotoxicity. The lack of neuroprotection by postischemic treatment with LJ529 may not be surprising, because inflammatory responses are not involved in OGD/reoxygenation-evoked neurotoxicity. Some researchers have, however, reported anti-ischemic effect of A3AR agonists in cultured neurons. For example, chronic preischemic treatment of an A3AR agonist protected cortical neurons against OGD/reoxygenation-induced damage. ${ }^{15}$ Also, prolonged treatment of A3AR agonist before/during ischemia, but not with short exposure, reduced anoxic depolarization-evoked neuronal death and disrupted excitatory neurotransmission by OGD in rat hippocampal slices ${ }^{62}$ or against forebrain ischemia in gerbils. ${ }^{17}$ Because long-term treatment with an A3AR agonist may affect various cellular functions, the exact reason for disparities in results obtained by us and by other researchers needs to be further clarified. Although this is speculative, the treatment time-dependent anti-ischemic effect of A3AR-mediated effects may be due to temporal difference of endogenous adenosine outflow under ischemia, ${ }^{63,64}$ as well as changes in receptor desensitization, internalization, and/or down-regulation of adenosine receptors. ${ }^{65}$

In summary, although LJ529 does not modulate the excitotoxicity and oxidative stress that are well-known neurotoxic factors in the early phase of ischemia, it markedly reduces cerebral infarct through activation of the A3AR, possibly via suppression of microglia/monocyte accumulation into the ischemic lesions and their inflammatory responses. Considering that the short therapeutic time window for effective treatment of cerebral ischemic stroke may be due to delayed but sustained inflammatory responses, A3AR agonists (including LJ529) could represent an attractive therapeutic drug for the treatment of postischemic injury. Moreover, because multiple pathways leading to neuronal death are activated in cerebral ischemia, a combination of drugs rather than single-drug treatment may be required for efficient neuroprotection. In support of this notion, the three-drug cocktail of minocycline (an antimicrobial agent with anti-inflammatory properties), riluzole (a glutamate antagonist), and nimodipine (a calcium channel blocker) has been reported to exert significant neuroprotection in a focal ischemic mouse model. ${ }^{66}$ Thus, an optimal therapy combining the antiinflammatory drug LJ529 with certain drugs with antioxidant and/or anti-excitotoxic activities may also be advantageous. 


\section{References}

1. Dirnagl U, ladecola C, Moskowitz MA: Pathobiology of ischaemic stroke: an integrated view. Trends Neurosci 1999, 22:391-397

2. Margaill I, Parmentier S, Callebert J, Allix M, Boulu RG, Plotkine M: Short therapeutic window for MK-801 in transient focal cerebral ischemia in normotensive rats. J Cereb Blood Flow Metab 1996, 16:107113

3. Hatfield RH, Gill R, Brazell C: The dose-response relationship and therapeutic window for dizocilpine (MK-801) in a rat focal ischaemia model. Eur J Pharmacol 1992, 216:1-7

4. Valtysson J, Hillered L, Andiné P, Hagberg H, Persson L: Neuropathological endpoints in experimental stroke pharmacotherapy: the importance of both early and late evaluation. Acta Neurochir (Wien) 1994, 129:58-63

5. Von Lubitz DK, McKenzie RJ, Lin RC, Devlin TM, Skolnick P: MK-801 is neuroprotective but does not improve survival in severe forebrain ischemia. Eur J Pharmacol 1993, 233:95-100

6. Colbourne F, Li H, Buchan AM, Clemens JA: Continuing postischemic neuronal death in CA1: influence of ischemia duration and cytoprotective doses of NBQX and SNX-111 in rats. Stroke 1999, 30:662-668

7. Price CJ, Warburton EA, Menon DK: Human cellular inflammation in the pathology of acute cerebral ischaemia. J Neurol Neurosurg Psychiatry 2003, 74:1476-1484

8. Dixon AK, Gubitz AK, Sirinathsinghji DJ, Richardson PJ, Freeman TC: Tissue distribution of adenosine receptor mRNAs in the rat. $\mathrm{Br} J$ Pharmacol 1996, 118:1461-1468

9. Atkinson MR, Townsend-Nicholson A, Nicholl JK, Sutherland GR, Schofield PR: Cloning, characterisation and chromosomal assignment of the human adenosine A3 receptor (ADORA3) gene. Neurosci Res 1997, 29:73-79

10. Bar-Yehuda S, Silverman MH, Kerns WD, Ochaion A, Cohen S, Fishman $P$ : The anti-inflammatory effect of $A 3$ adenosine receptor agonists: a novel targeted therapy for rheumatoid arthritis. Expert Opin Investig Drugs 2007, 16:1601-1613

11. Ochaion A, Bar-Yehuda S, Cohen S, Barer F, Patoka R, Amital H, Reitblat T, Reitblat A, Ophir J, Konfino I, Chowers Y, Ben-Horin S, Fishman $P$ : The anti-inflammatory target $A(3)$ adenosine receptor is over-expressed in rheumatoid arthritis, psoriasis and Crohn's disease. Cell Immunol 2009, 258:115-122

12. Haskó G, Németh ZH, Vizi ES, Salzman AL, Szabó C: An agonist of adenosine $A 3$ receptors decreases interleukin-12 and interferongamma production and prevents lethality in endotoxemic mice. Eur J Pharmacol 1998, 358:261-268

13. Wagner R, Ngamsri KC, Stark S, Vollmer I, Reutershan J: Adenosine receptor A3 is a critical mediator in LPS-induced pulmonary inflammation. Am J Physiol Lung Cell Mol Physiol 2010, 299:L502-L512

14. Ge ZD, van der Hoeven D, Maas JE, Wan TC, Auchampach JA: A(3) adenosine receptor activation during reperfusion reduces infarct size through actions on bone marrow-derived cells. J Mol Cell Cardiol 2010, 49:280-286

15. Chen GJ, Harvey BK, Shen H, Chou J, Victor A, Wang Y: Activation of adenosine $A 3$ receptors reduces ischemic brain injury in rodents J Neurosci Res 2006, 84:1848-1855

16. Fedorova IM, Jacobson MA, Basile A, Jacobson KA: Behavioral characterization of mice lacking the $A 3$ adenosine receptor: sensitivity to hypoxic neurodegeneration. Cell Mol Neurobiol 2003, 23:431447

17. Von Lubitz DK, Lin RC, Popik P, Carter MF, Jacobson KA: Adenosine A3 receptor stimulation and cerebral ischemia. Eur $J$ Pharmacol 1994, 263:59-67

18. Von Lubitz DK, Simpson KL, Lin RC: Right thing at a wrong time? Adenosine A3 receptors and cerebroprotection in stroke. Ann N Y Acad Sci 2001, 939:85-96

19. Kim HO, Ji XD, Siddiqi SM, Olah ME, Stiles GL, Jacobson KA: 2-Substitution of N6-benzyladenosine-5'-uronamides enhances selectivity for A3 adenosine receptors. J Med Chem 1994, 37:36143621

20. Tchilibon S, Joshi BV, Kim SK, Duong HT, Gao ZG, Jacobson KA: (N)-methanocarba 2,N6-disubstituted adenine nucleosides as highly potent and selective A3 adenosine receptor agonists. J Med Chem 2005, 48:1745-1758
21. Jeong LS, Jin DZ, Kim HO, Shin DH, Moon HR, Gunaga P, Chun MW, Kim YC, Melman N, Gao ZG, Jacobson KA: N6-substituted D-4'thioadenosine-5'-methyluronamides: potent and selective agonists at the human A3 adenosine receptor. J Med Chem 2003, 46:3775-3777

22. Belayev L, Alonso OF, Busto R, Zhao W, Ginsberg MD: Middle cerebral artery occlusion in the rat by intraluminal suture. Neurological and pathological evaluation of an improved model. Stroke 1996, 27:1616-1622; discussion 1623

23. Li AH, Moro S, Melman N, Ji XD, Jacobson KA: Structure-activity relationships and molecular modeling of 3,5-diacyl-2,4-dialkylpyridine derivatives as selective A3 adenosine receptor antagonists. J Med Chem 1998, 41:3186-3201

24. Zocchi C, Ongini E, Conti A, Monopoli A, Negretti A, Baraldi PG, Dionisotti S: The non-xanthine heterocyclic compound $\mathrm{SCH} 58261$ is a new potent and selective $\mathrm{A} 2 \mathrm{a}$ adenosine receptor antagonist. J Pharmacol Exp Ther 1996, 276:398-404

25. Ge ZD, Peart JN, Kreckler LM, Wan TC, Jacobson MA, Gross GJ, Auchampach JA: Cl-IB-MECA [2-chloro-N6-(3-iodobenzyl)adenosine-5'-N-methylcarboxamide] reduces ischemia/reperfusion injury in mice by activating the $\mathrm{A} 3$ adenosine receptor. J Pharmacol Exp Ther 2006, 319:1200-1210

26. Melani A, Pantoni L, Bordoni F, Gianfriddo M, Bianchi L, Vannucchi MG, Bertorelli R, Monopoli A, Pedata F: The selective A2A receptor antagonist $\mathrm{SCH} 58261$ reduces striatal transmitter outflow, turning behavior and ischemic brain damage induced by permanent focal ischemia in the rat. Brain Res 2003, 959:243-250

27. Popoli P, Reggio R, Pezzola A: Effects of SCH 58261, an adenosine $A(2 A)$ receptor antagonist, on quinpirole-induced turning in 6-hydroxydopamine-lesioned rats. Lack of tolerance after chronic caffeine intake. Neuropsychopharmacology 2000, 22:522-529

28. Yang Y, Shuaib A, Li Q: Quantification of infarct size on focal cerebral ischemia model of rats using a simple and economical method. J Neurosci Methods 1998, 84:9-16

29. Swanson RA, Morton MT, Tsao-Wu G, Savalos RA, Davidson C, Sharp FR: A semiautomated method for measuring brain infarct volume. J Cereb Blood Flow Metab 1990, 10:290-293

30. Ju C, Oh YJ, Han BH, Kim HS, Kim HC, Kim WK: Intracellular pHdependent peroxynitrite-evoked synergistic death of glucose-deprived astrocytes. Free Radic Biol Med 2004, 37:1160-1169

31. Waggoner AS: Dye indicators of membrane potential. Annu Rev Biophys Bioeng 1979, 8:47-68

32. Schmidt HH, Warner TD, Nakane M, Förstermann U, Murad F: Regulation and subcellular location of nitrogen oxide synthases in RAW264.7 macrophages [Erratum appeared in Mol Pharmacol 1992, 42:174]. Mol Pharmacol 1992, 41:615-624

33. Chen JF, Pedata F: Modulation of ischemic brain injury and neuroinflammation by adenosine A2A receptors. Curr Pharm Des 2008 , 14:1490-1499

34. Lee JC, Cho GS, Kim HJ, Lim JH, Oh YK, Nam W, Chung JH, Kim WK: Accelerated cerebral ischemic injury by activated macrophages/microglia after lipopolysaccharide microinjection into rat corpus callosum. Glia 2005, 50:168-181

35. Sajjadi FG, Takabayashi K, Foster AC, Domingo RC, Firestein GS: Inhibition of TNF-alpha expression by adenosine: role of A3 adenosine receptors. J Immunol 1996, 156:3435-3442

36. Lee JY, Jhun BS, Oh YT, Lee JH, Choe W, Baik HH, Ha J, Yoon KS, Kim SS, Kang I: Activation of adenosine A3 receptor suppresses lipopolysaccharide-induced TNF-alpha production through inhibition of PI 3-kinase/Akt and NF-kappaB activation in murine BV2 microglial cells. Neurosci Lett 2006, 396:1-6

37. Haskó G, Szabó C, Németh ZH, Kvetan V, Pastores SM, Vizi ES: Adenosine receptor agonists differentially regulate IL-10, TNF-alpha, and nitric oxide production in RAW 2647 macrophages and in endotoxemic mice. J Immunol 1996, 157:4634-4640

38. Bowlin TL, Borcherding DR, Edwards CK 3rd, McWhinney CD: Adenosine A3 receptor agonists inhibit murine macrophage tumor necrosis factor-alpha production in vitro and in vivo. Cell Mol Biol (Noisyle-grand) 1997, 43:345-349

39. Hall A: Rho GTPases and the actin cytoskeleton. Science 1998 279:509-514

40. Jones GE: Cellular signaling in macrophage migration and chemotaxis. J Leukoc Biol 2000, 68:593-602

41. Sánchez-Madrid F, del Pozo MA: Leukocyte polarization in cell migration and immune interactions. EMBO J 1999, 18:501-511 
42. Hendriks JJ, Alblas J, van der Pol SM, van Tol EA, Dijkstra CD, de Vries HE: Flavonoids influence monocytic GTPase activity and are protective in experimental allergic encephalitis. J Exp Med 2004, 200:1667-1672

43. Honing $H$, van den Berg TK, van der Pol SM, Dijkstra CD, van der Kammen RA, Collard JG, de Vries HE: RhoA activation promotes transendothelial migration of monocytes via ROCK. J Leukoc Biol 2004, 75:523-528

44. Tyrala EE, Chen X, Boden G: Glucose metabolism in the infant weighing less than 1100 grams. J Pediatr 1994, 125:283-287

45. Jordan J, Segura T, Brea D, Galindo MF, Castillo J: Inflammation as therapeutic objective in stroke. Curr Pharm Des 2008, 14:3549-3564

46. van der Hoeven D, Wan TC, Auchampach JA: Activation of the A(3) adenosine receptor suppresses superoxide production and chemotaxis of mouse bone marrow neutrophils. Mol Pharmacol 2008, 74:685-696

47. Amantea D, Nappi G, Bernardi G, Bagetta G, Corasaniti MT: Postischemic brain damage: pathophysiology and role of inflammatory mediators. FEBS J 2009, 276:13-26

48. Brouns R, De Deyn PP: The complexity of neurobiological processes in acute ischemic stroke. Clin Neurol Neurosurg 2009, 111:483-495

49. Martin L, Pingle SC, Hallam DM, Rybak LP, Ramkumar V: Activation of the adenosine A3 receptor in RAW 264.7 cells inhibits lipopolysaccharide-stimulated tumor necrosis factor-alpha release by reducing calcium-dependent activation of nuclear factor-kappaB and extracellular signal-regulated kinase 1/2. J Pharmacol Exp Ther 2006, 316: 71-78

50. Szabó C, Scott GS, Virág L, Egnaczyk G, Salzman AL, Shanley TP, Haskó G: Suppression of macrophage inflammatory protein (MIP)1alpha production and collagen-induced arthritis by adenosine receptor agonists. Br J Pharmacol 1998, 125:379-387

51. Salvatore CA, Tilley SL, Latour AM, Fletcher DS, Koller BH, Jacobson MA: Disruption of the $A(3)$ adenosine receptor gene in mice and its effect on stimulated inflammatory cells. J Biol Chem 2000, 275:4429_ 4434

52. Jacobson KA: Adenosine A3 receptors: novel ligands and paradoxical effects. Trends Pharmacol Sci 1998, 19:184-191

53. Ramakers BP, Riksen NP, Rongen GA, van der Hoeven JG, Smits $P$, Pickkers $P$ : The effect of adenosine receptor agonists on cytokine release by human mononuclear cells depends on the specific Tolllike receptor subtype used for stimulation. Cytokine 2006, 35:95-99

54. van der Putten C, Zuiderwijk-Sick EA, van Straalen L, de Geus ED, Boven LA, Kondova I, IJzerman AP, Bajramovic JJ: Differential expression of adenosine $A 3$ receptors controls adenosine $A 2 A$ receptor-mediated inhibition of TLR responses in microglia. J Immunol 2009, 182:7603-7612
55. Walker BA, Jacobson MA, Knight DA, Salvatore CA, Weir T, Zhou D, Bai TR: Adenosine A3 receptor expression and function in eosinophils. Am J Respir Cell Mol Biol 1997, 16:531-537

56. Walters CE, Pryce G, Hankey DJ, Sebti SM, Hamilton AD, Baker D, Greenwood J, Adamson P: Inhibition of Rho GTPases with protein prenyltransferase inhibitors prevents leukocyte recruitment to the central nervous system and attenuates clinical signs of disease in an animal model of multiple sclerosis. J Immunol 2002, 168:4087-4094

57. Allen WE, Jones GE, Pollard JW, Ridley AJ: Rho, Rac and Cdc42 regulate actin organization and cell adhesion in macrophages. J Cell Sci 1997, 110:707-720

58. Worthylake RA, Lemoine $\mathrm{S}$, Watson JM, Burridge $\mathrm{K}$ : RhoA is required for monocyte tail retraction during transendothelial migration. J Cell Biol 2001, 154:147-160

59. Xu J, Wang F, Van Keymeulen A, Herzmark P, Straight A, Kelly K, Takuwa Y, Sugimoto N, Mitchison T, Bourne HR: Divergent signals and cytoskeletal assemblies regulate self-organizing polarity in neutrophils. Cell 2003, 114:201-214

60. Abbracchio MP, Rainaldi G, Giammarioli AM, Ceruti S, Brambilla R, Cattabeni F, Barbieri D, Franceschi C, Jacobson KA, Malorni W: The A3 adenosine receptor mediates cell spreading, reorganization of actin cytoskeleton, and distribution of Bcl-XL: studies in human astroglioma cells. Biochem Biophys Res Commun 1997, 241:297-304

61. Abd-El-Basset EM, Prashanth J, Ananth Lakshmi KV: Up-regulation of cytoskeletal proteins in activated microglia. Med Princ Pract 2004 13:325-333

62. Pugliese AM, Coppi E, Volpini R, Cristalli G, Corradetti R, Jeong LS, Jacobson KA, Pedata $F$ : Role of adenosine A3 receptors on CA1 hippocampal neurotransmission during oxygen-glucose deprivation episodes of different duration. Biochem Pharmacol 2007, 74:768-779

63. Hagberg H, Andersson P, Lacarewicz J, Jacobson I, Butcher S, Sandberg M: Extracellular adenosine, inosine, hypoxanthine, and xanthine in relation to tissue nucleotides and purines in rat striatum during transient ischemia. J Neurochem 1987, 49:227-231

64. Latini S, Bordoni F, Corradetti R, Pepeu G, Pedata F: Temporal correlation between adenosine outflow and synaptic potential inhibition in rat hippocampal slices during ischemia-like conditions. Brain Res 1998, 794:325-328

65. Klaasse EC, Ijzerman AP, de Grip WJ, Beukers MW: Internalization and desensitization of adenosine receptors. Purinergic Signal 2008 , 4:21-37

66. Weng YC, Kriz J: Differential neuroprotective effects of a minocyclinebased drug cocktail in transient and permanent focal cerebral ischemia. Exp Neurol 2007, 204:433-442 